\title{
Dissociations Between Language and Cognition: Cases and Implications
}

\author{
Susan Curtiss \\ Universily of California, Los Angeles
}

An important issue for the cognitive sciences is whether grammar is to any nontrivial extent an autonomous cognitive system. Current cognitive hypotheses of language acquisition would argue against an autonomous linguistic system and would support the notion that language emerges from more general cognitive knowledge and is throughout its development fundamentally tied to a nonlinguistic cognitive base. This paper explores this iscue and presents data from case studies of children showing clear dissociations between language and nonlanguage cognitive abilities. The implications of such data are discussed. The major implications appear to be that lexical and relational semantic abilities are deeply linked to broader conceptual development but morphological and syntactic abilities are not. The development of a normal linguistic system, however, one in which grammar is systematically related to meaning, requires concurrent and concomitant linguistic and nonlingustic cognitive development.

\section{THE ISSUES}

A central question of linguistic theory remains essentially unanswered, namely, how does a child acquire language? This question involves several key issues: issues concerning the quality and quantity of input necessary for language acquisition to occur, and issues concerning the nature of the neuropsychological and cognitive abilities the child must bring to the language-learning task. Researchers addressing these issues have postulated constraints on the linguistic input to the child, on the cognitive capacity of the child, or both, thereby theoretically reducing the necessary complexity of the acquisition process. 
Many investigators, in studying input, have stressed the importance of the environment in the acquisition process (Snow, 1972; Zukow, Reilly, \& Greenfield, 1979; Braunwald, 1978; Braunwald \& Brislin, 1979; ErvinTripp \& Miller, 1977; Nelson, 1976). Such studies have claimed that "motherese" presents restricted and simple data to the language-learning child, and this simplified model in conjunction with the clarifying role motherese plays facilitates acquisition. Such studies have further argued that the embedding of language in social interaction involving nonlinguistic information as well as linguistic information also serves to aid the child in acquiring language.

\section{Input Explanations}

Recent studies have countered this position (1) by pointing out that the notion simple is as yet undefined; (2) by demonstrating that using even illdefined notions of simplicity, motherese is not transparently linguistically simple, at least in terms of frequency of simple sentences, of simple sentential relations, of direct pairings of form and function relations, or of mother's clarifications (e.g., expansions and repairs) (Newport, Gleitman, \& Gleitman, 1977; Shatz, 1979, in press); (3) by demonstrating that nonlinguistic information in mother-child interactions (e.g., gestures) is not related simply or directly to specific aspects of language; and (4) by demonstrating that the caretaker does not adapt the linguistic and nonlinguistic information she provides to the child's developing linguistic knowledge (Newport et al., 1977; Shatz, 1979, in press). What is more, work by Schiff (1979) suggests that even with substantially limited and impoverished input, language acquisition can proceed normally.

More importantly, perhaps, studies that have stressed the importance of environmental factors constraining the task of acquisition have generally failed to propose the mechanisms by which input data and nonlinguistic information are utilized by the child to acquire language. The environment undoubtedly plays an important role in language acquisition. However, identifying this role may best serve to elucidate what the environment does not provide and thus the kinds of child-internal mechanisms that must be at play.

\section{Cognitive Explanations}

Studies focusing on the cognitive capacities of the child have stressed constraints in these capacities, pointing to limitations on memory, production and processing capacity, and computational ability (Bloom, 1970; 
Menyuk, 1964, 1977; Ervin-Tripp, 1970; Cromer, 1974; Mchler, 1971). Again, the central question arises of how these general cognitive limitations explain how a child acquires language. To what extent, for example, can processing limitations and strategies serve as language-learning mechanisms? Slobin $(1973,1979)$ and Newport et al. (1977) have suggested specific strategies that may aid the child in focusing attention on crucial grammatical information or form-meaning pairings during the earlicst stages of acquisition. But in what sense do processing stratcgies and cognitive limitations on memory and computational ability learn language, i.e., determine the structural properties peculiar to the input language and construct a grammar for it? One might argue that such processing strategies and computational abilities constrain the class of possible human languages. But this has not been demonstrated to date. In addition, to rely on such factors to account for acquisition in the early stages does not explain how a child can progress from the earliest grammars to the adult grammar. Primarily gestalt-like, visually-perceptually based strategies, hypothesized to be the major general information-processing strategies in children under 5 (Klahr \& Wallace, 1976; Piaget \& Morf, 1958) seem hardly appropriate to serve as discovery procedures for the highly specific features of a grammar.

These questions raise an additional critical issue in an attempt to account for language acquisition-whether language acquisition is performed by general learning mechanisms not specific to the learning of language or whether acquisition is performed by language-specific learning mechanisms. In both interactional-based models and cognition-based models of acquisition, a widely held assumption is that language acquisition shares a common cognitive basis with nonlanguage behavior (Bates, 1976, 1979; Garnica, 1978; Sinclair, 1975a, 1975b; Greenfield, 1976, 1978; Greenfield \& Schneider, 1977). In many instances language acquisition is seen as a process of mapping linguistic structures onto structurally parallel nonlinguistic systems of knowledge that the child already has, for example, action patterns. The mechanism underlying such a mapping process is presumably analogy (cf. Bruner, 1975), but once again it begs the question to propose a general learning mechanism of analogy without characterizing the way in which the child as analogy-maker constructs analogies between systems whose similarities and relationships are hardly direct or transparent.

Nonetheless, the view that language acquisition has a nonlinguistic cognitive basis persists, and much developmental psycholinguistic research has looked for the roots of language ability in sensorimotor intelligence. Sesnorimotor knowledge which has been hypothesized to be prerequisite to or significantly related to early language development includes the general 
emergence of representational thought and symbolic capacity as evidenced in deferred imitation, the use of communicative gestures, and symbolic play (Inhelder, Lezine, Sinclair, \& Stambak, 1972; Sinclair, 1975a, 1975b; Brown, 1973), the attainment of object permanence (Bloom, 1973; Sinclair, 1975a; Corrigan, 1978), the knowledge that other people can serve as agents (Bates, 1976; Clark, 1977), and the ability to use novel actions or means to serve familiar ends (Bates, Benigni, Bretherton, Camaioni, \& Volterra, 1977; Inhelder et al., 1972). Specific claims have related certain of these cognitive attainments to the acquisition of particular semantic categories (e.g., agent and location [Brown, 1973; Edwards, 1973], nonexistence and recurrence [Corrigan, 1978]), the development of semantic fields (Nelson, 1974), the early use of referential words (Bloom, 1973), the early component-structure of word meanings (Clark, 1971, 1973), rapid increases in vocabulary (Ingram, Note 1; Corrigan, 1978), the acquisition and use of specific communicative functions (Bates, 1976), semantic aspects of word use (Dihoff \& Chapman, 1977; Ingram, Note 1), and onset of two-word combinations (Corrigan, 1978; Folger \& Leonard, 1978).

Much of the research into ties between language and nonlanguage aspects of cognition has carried the implicit assumption that abilities emerging at the same point in development reflect common underlying cognitive knowledge. This work also commonly takes positive correlations between emerging abilities as evidence that they are in some way causally linked, or at least based on a shared cognitive organizing principle. But positive correlations in the normally developing child are not hard to come by. Hair growth and language development might be positively correlated, but few psycholinguists would wish to posit interesting links between the two. Thus positive correlations between sensorimotor attainments and specific language attainments might be artifactual, reflecting general cortical maturation instead of shared mechanisms or principles. The earlier onset of language acquisition noted in some children acquiring American Sign Language as a first language (McIntire, 1977; Schlessinger \& Meadow, 1972; Mindel \& Vernon, 1971) is consistent with the interpretation that the onset of language is a function of cortical maturation of which, somewhat unrelatedly, sensorimotor intelligence is also a reflex. Thus earlier maturation of visual cortex permits ealier onset of language performed in a visual modality, whereas later maturation of auditory cortex (Bay, 1975) underlies the later acquisition of spoken language, both, perhaps, independent of particular sensorimotor knowledge.

The problem in interpreting positive correlations in normal development lies in the fact that since many areas develop simultaneously in a normal child, it is difficult to tease out the relationships and interdependencies (and independencies) involved. However, children who display 
dissociations in cognitive function can reveal which areas of development may actually be independent. Correlations between functions that persist in the face of these dissociations are stronger evidence for an underlying dependent relationship between them than are similar correlations found with normals. By looking in particular at dissociations between language and cognition in development, we may better determine the necessary relationships between language and nonlanguage abilities, and thereby be a step closer to characterizing the mechanisms involved in language acquisition. We will at least be closer to knowing whether they are general or specific to language.

\section{DATA}

In the remainder of this paper I will present data from children who show dissociations between language and nonlanguage cognitive abilities. In each instance the child being discussed has been the subject of a detailed case study examining not only language but a range of nonlanguage abilities hypothesized to be linked to language: drawing, symbolic play, auditory short-term memory, figure-ground perception, action manipulations including nesting and the building of hierarchical structures, logical/ temporal sequencing, and a variety of Piagetian tasks including tasks of classification, conservation, and topographical and Euclidean relations. (Other areas were also examined but will not be discussed for lack of space.) Only a few cases can be touched on and only brief discussion of the relevant data is possible, but the reader will be referred to more complete descriptions.

\section{Genie: Grammatical Deficit}

The first case to be discussed is one extensively described in the literature (Curtiss, Fromkin, Krashen, Rigler, \& Rigler, 1974: Fromkin, Krashen, Curtiss, Rigler, \& Rigler, 1974; Curtiss, 1977, 1979) of a girl (Genie) isolated from the age of 20 months to the age of 13 years 7 months. During her years of isolation she was purposely not spoken to, nor could she hear family conversation or any other language occurring in her home other than swearing (there was no TV or radio in the home.) Thus, although it is reported that she did speak several words before her isolation, she emerged from isolation with no spoken language and no comprehension of any language save a few isolated words. Since her discovery, she has learned some language, certain aspects in particular. The course of her linguistic de- 
velopment has paralleled that of normal children only in general ways (e.g., first single words, then two-word combinations, three-word combinations, etc.). Two ways in which her language development has differed from that of normal children will be detailed here (for a more complete description of her language development, see Curtiss, 1977).

The first area of difference is Genie's semantic ability.' Her acquisition of vocabulary was rapid and extensive; she had a vocabulary of approximately 100 words before she combined words, far more than normal children before the 2 -word stage. Her early vocabulary differed considerably from that of normals, whose early lexicons usually consist mainly of particles, rejoinders, and basic class nouns and verbs. Hers included colors and numbers, shape and size terms, supraordinate, basic, and subordinate class terms (e.g., jacket, dress, etc.; clothes, cat, dog, etc.; and animal). Genie sought out vocabulary to differentiate between similar objects that she recognized as different along some parameter, such as visual or functional (e.g., safety pin vs. straight pin, pen vs. pencil). Before combining words, Genie talked about nonpresent people and objects, and not only to request items or to indicate that she associated a particular item with a particular person, as do normal children, but to request that people talk to her about specific memories or about events to come that had been mentioned previously.

When Genie began combining words she produced mostly attributive structures, expressing possession, visual detail, and emotional states ("Valerie mother coat," "small two cup," "little white clear box," "Curtiss angry"). As her utterances became longer, time adverbials appeared (after, long time ago, now, tomorrow). She also began combining phrases, and expressed not only temporal relations ("Genie Mama have a father long time ago," "After dinner use mix-master") but causal and conditional relations as well ("Father make Genie cry," "Neal not come, happy. Neal come, sad"). Genie also has consistently responded appropriately to comments and questions, even quite complex ones, showing an understanding of illocutionary force, assertion, and inference.

$$
\begin{aligned}
&(A=\text { adult; } G=\text { Genie }) \text { A: Do you want me to play the piano } \\
& \text { for you a little bit? } \\
& \text { G: Long time. }
\end{aligned}
$$

\footnotetext{
iSemanrics is used here to refer to expression and comprehension of lexical meaning, meaning relations as expressed by word coenbinations (whether syntactically well formed of ill formed). and semantic/pragmatic notions of inference, assertion, and illocutionary force. No claim is made that Genie or any of the other cases being discussed has acquired a semantic system in a more formal sense, in which meaning is grammaticalized by specific linguistic structure.
} 
A: How's the neck?

G: Feel better.

A: I told you it would feel better when you got to school.

G: Hurt.

A: It hurts? I thought it felt better.

G: Little hurt.

A: How should I reach it?

G: Get ladder.

A: Why aren't you singing?

G: Very sad.

A: Why are you feeling sad?

G: Lisa sick.

A: How many sides does a triangle have?

G: Three.

A: How many sides does a circle have?

G: Round.

The second manner in which Genie's language differs from the normal pattern is in the disparity between her syntax and semantics. Through all of the semantic development described above, covering a period of several years, Genie has acquired very little syntax or morphology. There is practically no morphological elaboration in her utterances, such as use of plural or possessive markers or auxiliary forms, and no employment of syntactic devices or operations such as relativization, pronominalization, or movement of constituents as in subject-auxiliary inversion for questions. In addition, Genie's language contains no demonstratives; no proforms such as third-person pronouns, wh question words, or relative markers; no conjunctions such as but or if; and no auxiliary forms such as copulas or modals. What results is the stringing together of content words, often with rich and clear meaning but with little grammatical structure ("I like hear music ice cream truck," "Think about Mama love Genie," "At school teacher give block," "Sick people in ambulance," "Dentist say drink water"). Thus she shows a profile of primitive syntactic and morphological ability combined with relatively well-developed semantic ability (cf. footnote 1).

Genie's semantic sophistication suggests a conceptual level far surpassing what one would imagine from her otherwise rather primitive utterance. This impression is borne out through testing. In 1977 , at the age of $191 / 2-20$, she was in the concrete operational stage, performing at or above a 10-year-level on stercognosis, on figure-ground tasks, 
on a test of topographical and Euclidean relations, and on a test for decentrism of visual perspective. She conserved for area, length, and (questionably) number. Her drawing was at a 6- to 7-year level. She was able to perform all nesting operations tested and effortlessly constructed stick and block structures involving several layers of hierarchical structure, including Greenfield's (1978; Greenfield \& Schneider, 1977) models as well as several more complex structures. She performed all classification tasks perfectly (sorting on the principles of gender, animacy, and others), and sequenced all "picture-stories" correctly. In addition, her mental age has increased 1 year for every year since her discovery. In contrast, her auditory short-term memory is at a 3.0-year level. (See Curtiss, 1979; Curtiss, Fromkin, \& Yamada, Note 2, for more complete description of the tests and test results.)

Genie's profile of abilities (as judged by test performance) demonstrates that the cognitive knowledge of preoperational and even concrete operational intelligence is insufficient for the acquisition of syntax and morphology. Although the normative data that would allow for an age assessment of her semantics are lacking, her semantic ability suggests a tie between semantic development (in the narrow sense used here) and more general conceptual development. Her profile also suggests a potential link between auditory short-term memory and expressive syntax and morphology.

\section{Antony: Cognitive Deficit in a Young Child}

Antony is a mentally retarded boy who was studied at the age of 6.5-7.2..$^{2}$ IQ estimates range from 50 to 56 , and mental age, less than 1 year prior to our study, was 2.9 . Onset of speech is reported to have been at 1 year, with "full sentences" at 3 years. At the time we studied Antony, he had an impressive range of syntactic structures and considerable morphological elaboration and had acquired the very elements notably absent from Genie's speech. His speech contained third-person pronouns, demonstratives, infinitive markers, object sentential complements, wh pronouns, and close to the full range of auxiliary forms ("I tell him what you done," "I want to see who's in that class," "I don't know where's her arms," "Are you Mrs. W?"). Although Antony made errors that suggested he was still mastering some syntactic and morphological rules, more intriguingly he fre- 
quently produced sentences that were grammatically well formed (out of context) but semantically inappropriate:

J: Does your Daddy stay home all day and cook?

A: Nope. He was not comin' home.

J: What would you do if you were at home and you wanted some ice cream?

A: I would not have an ice cream! (said with intonation implying, "1 don't have an ice cream!")

In addition to inappropriate use of modal auxiliaries, Antony used tenses inconsistently ("He shot him. He shoot him. Police shoot him." [Spoken one right after the other]). He also occasionally used the wrong wh word in questions ("Where I took?" for "What'd I take?").

Antony frequently showed semantic immaturity in responses to questions. He was unable to respond to how or why questions (Genie responded correctly to all question types), frequently misinterpreted questions as assertions as in the ice cream example above, and often misunderstood the inferential content of utterances:

S: You sew with that (explaining a spool).

A: No, I don't sew with that.

S: Other people do.

A: No, my mom do.

$\mathrm{J}$ : Draw a picture of Vivian.

A: No. It's not Vivian's, it's mine.

S: Draw a picture of Mrs. W.

A: No. It's not Mrs. W's.

S; Draw a picture of Antony.

A: That's not me. This is me (pointing to himself).

His frequent failure to understand inference was paralleled by semantically and pragmatically bizarre utterances of his own, often involving deictic forms, so that communicating with Antony was often quite difficult; c.g.,

(A teacher, Miss C, had just entered the class and was standing within full view of Antony)

A: You guys, look it who's in our class. I want to see who's in that class.

S: Who's in what class?

A: No, in ours.

S: Everybody's here.

A: Not Miss C. 
In contrast to Genie, Antony's syntax and morphology appears to far outstrip his semantics. In context, Genie's utterances, though agrammatic, are clearly interpretable and unambiguous. Antony's speech in contrast, looks best out of context; it is usually well formed grammatically but often semantically inappropriate and confusing.

Other aspects of Antony's mental profile also contrast with Genie's. His drawing was at the prerepresentational level, he was unable to nest more than five seriated cups (a 28- to 32-month-old performance (Greenfield, Nelson, \& Saltzman, 1972)), and he was unable to copy any stick or block model involving hierarchical structure (able only to stack vertically or horizontally). He could not construct logical picture sequences and could not be tested for conservation or preoperational abilities because he failed to demonstrate comprehension of the concepts of same, more, and winner. In general contrast to Genie, who quickly learned the nature of a task, Antony extremely difficult to test, had a markedly short attention span, and often demonstrated an inability to understand a task. Moreover, it was not clear from his behavior whether Antony had achieved stage VI sensorimotor intelligence. Like Genie, however, Antony showed no symbolic play and displayed auditory short-term memory ability (7-year level) somewhat comparable to his level of syntactic/morphological ability and not to his semantic level.

We find once again with Antony's data, then, a possible link between auditory short-term memory and syntax and morphology, and an apparent tie between certain kinds of semantic knowledge and general conceptual level. Antony's case further suggests that preoperational and concrete operational intelligence are not only insufficient but may be unnecessary for acquisition of syntactic and morphological forms, although preoperational intelligence may be necessary for the systematic linking of such forms with meaning.

\section{Marta: Cognitive Deficit in an Adolescent}

Marta is a 16-year-old mentally retarded girl (IQ 44) (see Yamada, 1981a, 1981b for a more detailed description and analysis of both the linguistic and nonlinguistic data on this case). Marta is extremely verbal and therefore offers a special opportunity to examine linguistic ability in the face of substantial cognitive deficits. Since at $161 / 2$ she has probably reached the end point of her mental development, she also provides an opportunity to examine the potential for linguistic development in the face of such deficits.

Marta's syntactic and morphological abilities are richly developed. She produces sentences involving relativization, complementation, prono- 
minalization, passivization, and word-order reversals, and has full-blown noun phrase and verb phrase morphology ("Maybe I could play with a friend!" "He's my third principal I've had since I've been here." "She does paintings, this really good friend of the kids who I went to school with last year, and really loved."). Marta also uses an abundance of sentence adverbials and semantically rich and sophisticated lexical items, although proper nouns and specific nouns called for frequently elude her ("An' that's my regular friend, who normally will live by us, I think." "It's a week from Saturday an'..."').

In spite of the richness of her linguistic system, however, Marta's speech is often confusing or meaningless. Incorrect tense, aspect, pronouns, and adverb usage occur frequently ("An' she asked me out about a month." "We finally got that new Mexican cause his flight came in Wednesday month." "It's very soon that they asked us to fly out." S: "How many nights did you stay there?" M: "Oh, about four out of one." S: "His cousin flied in?" M: "It's flying in between ours [unintelligible]. So now it's between mine. He's my third principal, He will be my second principal."). Thus, although Marta's speech is abundant, her utterances often have the character of second- or third-order approximations to English, and they are ill formed semantically both in and out of context. ("She was thinking that it's no regular school, it's just plain old no buses, 'n' she heard." $\mathrm{S}$ : "When you mean your time's up, you mean it's your time to get a haircut?" M: "No, my mother took me in when the last time I've ever been in when, we came home.").

Marta is barely testable, has severely limited attentional capacity, and often cannot understand or perform tasks that normal 2-year-olds perform successfully. She appears, even at this late point in her development, to be at or just beyond sensorimotor stage VI. She has thus failed most tasks attempted and, on others, performed at an extremely low level, evidencing preschool-level drawing, an inability to copy even a simple bridge structure, and an inability to understand sorting tasks. In contrast to her great difficulty with tasks of conceptual ability and her poor performance to date on tests of auditory short-term memory, she easily performs sentence-repetition tasks, correcting minor phonological, syntactic, and morphological errors purposely presented to her. (See Yamada, 1981b, for a detailed account of Marta's interesting sentence-repetition performance.)

Marta's profile contrasts even more sharply with Genie's than Antony's does. Marta's speech is fluent, abundant, and richly structured; Genie's speech is belabored and agrammatic. Marta's speech is usually inappropriate and confusing both in and out of context. Genie's speech is always appropriate and usually clear in meaning in and out of context. Marta has severe attentional and conceptual deficits, causing her to perform poorly or fail to grasp almost all tasks. Genie has far superior attentional 
and conceptual abilities, enabling her to perform most tasks easily and well. Antony's profile is close to Marta's in conceptual and attentional capacity.

\section{DISCUSSION}

All three of the children described above show dissociations between their syntactic and morphological abilities, on the one hand, and their conceptual/semantic abilities, on the other. In addition, all three of these children display dissociations between grammatical ability and ability to perform action manipulations (see Curtiss, Yamada, \& Fromkin, 1979, for a discussion of this issue). A theory of language acquisition that weds grammatical acquisition to general cognitive development or to specific nonlanguage cognitive domains such as action (Bruner, 1968; Greenfield, 1978) cannot account for such cases. A learning theory proposing only general learning mechanisms not tied to the learning of any particular cognitive knowledge appears nonexplanatory in the face of the dissociations we find in selectively impaired development. More specialized learning mechanisms are indicated.

Genie and cases like hers (e.g., other isolated Children; Curtiss, 1980, 1981 ; and, perhaps, pidgin learners; Naro, 1973, 1979) may exemplify what kind of language develops with good nonlanguage cognitive abilities but impaired or nonfunctioning language acquisition mechanisms. Antony, Marta, and cases like theirs (see Curtiss et al., 1979; Yamada \& Curtiss, 1981) may indicate the kind of language that develops with well-functioning language acquisition mechanisms but impaired nonlanguage cognitive functions. Both kinds of cases suggest the existence of language-specific learning mechanisms that may be selectively intact or impaired."

If such mechanisms exist, there is evidence tying them to the left hemisphere. On the basis of clinical, experimental, anatomical, pharmacological, and radiological data (Woods \& Teuber, 1978; Molfese, 1972; Dennis \& Kohn, 1975; Dennis \& Whitaker, 1976; Day \& Ulatowska, 1979; Rankin, Aram, \& Horwitz, Note 3), it appears that the left hemisphere is specialized and prepotent for language at birth. This is especially true for right-

'Interestingly, both kinds of cases develop the structures and relations found in the one", two", and three-word utterances of early child language, those linguistic abilities found to correlate with sensorimotor intelligence. It remains an open question whether the carly use of words or word combinations reflects finguistic knowledge, i.e., knowledge of semantic or syntactic catezories, or father nonlinguistic, general conceptual eategories, of even simply nongeneralized pragmatic knowledge tying people and objects to specific contexts. It is possible that these early utterances represent linguistic performance before language-specific acquisition mechanisms are mature or functional. 
handers, and Genie is strongly right-handed, with familial sinistrality undetermined. Thus, in cases where we find developmental profiles like Genie's left-hemisphere impairment or inhibition is suggested. To wit, in Genie's case we have evidence that it is her right hemisphere that has been acquiring language (Fromkin et al., 1974; Curtiss, 1977; Curtiss, Fromkin, \& Krashen, 1978). Moreover, evidence from Genie and others (e.g., feral and isolated children [Curtiss, 1980, 1981] and pidgin learners [Naro, 1973, 1979]) supports the notion of a critical period for first language acquisition. It appears from these data that language-specific acquisition mechanisms may be functional only during this critical period. The language we find in cases like Genie, where acquisition occurs beyond the critical period, may therefore illustrate the outcome of acquisition attempted by non-languagespecific mechanisms. Indeed, we have in the past hypothesized functional atrophy of Genie's left hemisphere for language acquisition and processing (Fromkin et al., 1974; Curtiss, 1977; Curtiss et al., 1978). In cases where we find developmental profiles like Antony's or Marta's, islands of intact neural areas and noninhibited cortical control are suggested. Most likely these intact areas would be in the left hemisphere.

\section{CONCLUSION}

None of the cases described can be said to have normal language. In this light, it is interesting that none of them evidence consistent grammaticalization of meaning, i.e., semantics in a grammatical sense. While acquisition of syntax and morphology may to some extent proceed independently of other cognitive development, normal language in which meaning is systematically related to syntactic and morphological structure would seem to depend on the development of nonlinguistic cognitive knowledge alongside acquisition of the grammar.

Concomitant development of language and nonlanguage cognitive systems is the norm, and it is in this context of mutual development that normal language unfolds. However, in searching for an explanatory theory of the mechanisms of language acquisition, we must look not only at the psychological development in which language acquisition is embedded but also at its separability and possible independence from other aspects of the mind.

\section{REFERENCE NOTES}

1. Ingram, D. Srages in the development of one word utterances. Paper presested at Stanford Child Language Research Forum, Stanford University, Aprit 1974 
2. Curtiss, S., Fromkin, V., \& Yamada, J. The independence of langudge as a cognitrive sysrem. Unpublished manuscript, 1979.

3. Rankin, J., Aram, D., \& Horwitz, S. A comparison of right and leff hemiplegic ctildren's language ability. Paper presented at the eighth annual meeting of the International Neuroprychological Society, 1980.

\section{REFERENCES}

Bates, E. Langugge and cantext: The acquisition of pragmatics. New York: Academic Press, 1976.

Bates, F. The emergence of symbols. New York: Academic Press, 1979.

Bates, E., Benigni, L., Btetherton, I., Camaioni, L., \& Volterra, V. Cogntition and commur. mication from 9-13 months: A correlational study program on cognitive amd perceptual foctors in human development (Report No. 12). Institute for the Study of Intellectual Behavior. Boulder: University of Colorado, 1977.

Bay, E. Ontogeny of stable speech areas in the human brain. In E. H. Lenneberg \& E. Lenneberg (Eds.), Foundations of language develogment: $A$ multidisciplinary approach (Vol. 2). New York: Academic Press, 1975. Pp. 21-30.

Bloom, L. Language devefopment: Form and function in emerging grammars. Cambridge: M.I.T. Press, 1970.

Bloom, L. One word at a time. The Hague: Mouton, 1973.

Braunwald, S. Context, word, and meaning: Toward a communicational analysis of lexical acquisition, In A. Lock (Ed.), Acrion, gesture and symbol, London: Academic Press, 1978. Pp. 485-527.

Braunaald, S., \& Brislin, R. On being understood: The listener's contribution to the toddler's ability to communicate. In P. French (Ed.), The development of meaning. Hiroshima: Bunka Hyoron, 1979.

Brown, R. A first lenguage: The early stages, Cambridge: Harvard University Press, 1973.

Bruner, J. Processes of cognirive growth: Infancy. Worcester, Massachusetts: Clark University with Barre Publishers, 1968.

Bruner, J. The ontogenesis of speech acts. Journal of Child Langwage, 1975, 2, 1-20.

Clark, E. On the acquisition of the meaning of before and after. Journd of Verbal Learning and Verbol Behawior, 1971, 10, 266-275,

Clark, E. What's in a word: On the child's acquisition of semantics in his first languaze. In T. Moore (Ed.), Cognitive development and the acguisition of language. New York: Academic Press, 1973.

Clark, E. First language acquisition. In J, Morton (Ed.), Psycholinguistics: Developmental and pathological. New York: Cornell University Press, 1977. Pp. 3-72.

Corrigan, R. Language development as related to stage 6 object permanence development. Journal of Child Language, 1978, S, 173-190.

Cromer, R. Receptive language in the mentally retarded: Processes and diagnostic distiactions. In R. Schiefelbusch \& L. Lloyd (Eds.), Language perspectives: Acquisition, retardafion, and intervention. Baltimore: University Park Press, 1974, Pp. 237-268.

Curtiss, S. Genie: A psycholinguistic study of a modern-day "Wid Child." New York: Academic Press, 1977.

Curtiss, S. Genie: Language and cognition. UCL.A Working Papers in Cognitive Linguistics. $1979,1,15.62$.

Curtiss, S. A critical period for the acquisition of grammar: Evidence from feral and isolated children. UCL.A Working Popers in Cognirive Linguistics, 1980, 2, 21-36.

Curtiss, S. Feral children: A review. Mental Retardation: An Annwal Review, 1981.

Curtiss, S., Fromkin, V., \& Krashen, S. Language development in the mature (minor) right hemisphere. ITL: Review of Applied Linguistics, 1978, 39-40, 23-37.

Curtiss, S., Fromkin, V., Krashen, S., Rigler, D., \& Rigler, M. The linguistic development of Genie. Langwage, 1974, $50(3), 528.554$. 
Curtiss, S., Yamada, J., \& Fromkin, V. How independent is language? On the question of formal parallels between grammar and action. UCLA Working Papers in Cognitive Linguistics, 1979, 1, 131-157.

Day, P., \& Ulatowska, H. Perceptual, cognitive, and linguistic developenent after early hemispherectomy: Two case studies. Brain and Languoge, 1979, 7, 17.33.

Dennis, M., \& Kohn, B. Comprehension of syntax in infantile hemiplegies after cerebral bemidecortication: Left hemisphere superiority. Brain and Language, 1975, 2, 475485 .

Dennis, M., \& Whitaker, H. Language acquisition following hemidecortication: Linguistic superiority of the left over the right hemisphere. Brain and Languoge, 1976, 3(3). 404-433.

Diboff, R., \& Chapman, R. First words: Their origins in action. Papers and Reports on Child Languoge Development (Stanford University), 1977, 13, 1-7.

Edwards, D. Sensory-motor intelligence and semantic relations in early child grammar. Cog. nition, 1973, 2, 395-434.

Ervin-Tripp, S. Discourse agreement: How childrent answer questions. In J. Hayes (Ed.), Cognition and the development of language. New York: Wiley, 1970.

Ervin-Tripp, S., \& Miller, W. Early discourse: Some questions about questions. In M. Lewis \& L. Rosenblum (Eds.), Interaction, conversation, and the development of language. New York: Wiley, 1977.

Folger, M., \& Leonard, L. Language and sensorimotor development during the early period of referential speech. Journef of Speech and Hearing Research, 1978, 2l(3), 519-527.

Fromkin, V., Krashen, S., Curtiss, S., Rigler, D., \& Rigler, M. The development of language in Genie: A case of language acquisition beyond the "eritical period." Brain and Lan. guage, 1974, I, 81-107.

Garnica, $\mathbf{O}$. Non-verbal concomitants of language input to children. In $\mathrm{N}$. Waterson \& $\mathrm{C}$. Snow (Eds.), The development of communication. New York: Wiley, 1978.

Greenfield, P. The grammar of action in eognitive development. In C. Waiter, L. Rogers, \& J. Finzi-Fried (Eds.), Conference an human brain function, Los Angeles; BRI Publications Office, 1976.

Greenfield, P. Structural parallels between language and action in development, In A. Lock (Ed.). Action, gesture, and symbol: The emergence of language. London: Academic Press, 1978.

Greenfield, P., Nelson, K., \& Saltzman, E. The development of rule-bound strategies for manipulating seriated cups: A parallel between action and grammar. Cognitrive Psy. chology, 1972, 3, 291-310.

Greenfield, P.. \& Schneider, L. Building a tree structure: The development of hierarchical complexity and interrupted strategies in children's construction activity, Developmental Pyychology, 1977, /3(4), 299-313.

Inhelder, B., Lezine, I., Sinclair, H., \& Stambak, M. Les debuts de la fonetion symbolique. Archives Psychologiques, 1972, 41, 187-243.

Klahr, D., \& Wallace, J. Cognitive development: An information processing view. Hillsdale, New Jersey: Erlbaum, 1976.

McIntire, M. The acquisition of American Sign Language hand configurations. Sign Language Srudies, 1977, 16, 247-266.

Mehier, J. Stadies in language and thought developenent. In R. Huxley \& E. Ingram (Eds.). Language acquisition: Models and methods. New York: Academic Press, 1971. Pp. $201-225$.

Menyuk, P. Comparison of grammar of children with functionally deviant and normal speech. Jowrnal of Speech and Hearing Research, 1964, 7, 109-121.

Menyuk, P. Langmage and maturation. Cambridge, Mass; MIT Press, 1977.

Mindel, E., \& Vernon, M. They grow in silence: The deaf child and his family. Silverspring: National Association of the Deaf, 1971.

Molfese, D. Cerebral asymmetry in infants, children, and adults: Anditary evoked responses to speech and mussic stimuli. Unpublished doctoral dissertation, Pennsylvania State University, 1972. 
Naro, A. The origin of West African pidgin. In C. Corum, T. C. Smith-Stark, \& A. Weiser (Eds.), Papers from the Ninth Regional Merting. Chicago: Chicago Linguistic Society, 1973. Pp. 442-449.

Naro, A. A review of "Pidgin and creole linguistics" by A. Valdman (ed.). Language, $1979,55(4), 886-893$.

Nelson, K. Concept, word, and sentence: Interrelations in acquisition and development. Psychological Review, 1974, 81, 267-285.

Nelson, K. Facilitating children's syntax. Developmental Psychology, 1976, 13, 101-107.

Newport, E., Gleitman, H., \& Gleitman, L. Mother, I'd rather do it myself: Some effects and non-effects of maternal speech style. In C. Snow \& C. Ferguson (Eds.), Talking to children. Cambridge: Cambridge University Press, 1977.

Piaget, J., \& Morf, A. Les isomorphismes partiels entre les structures logiques et les structures perceptives. In J. Piaget (Ed.), Etudes d'epistemologie genetique (Vol. 6). Paris: Presses Universinaires de France, 1958.

Schiff, $\mathrm{N}$. The influence of deviant maternal input on the development of language during the preschool years. Journal of Speech and Hearing Reseurch, 1979, 22, 581-603.

Schlessinger, H., \& Meadow, K. Sownd and sizn. Berkeley: University of California Press, 1972.

Shatz, M. How to do things by asking: Form-function pairings in mothers' questions and their relations to children's responses. Child Development, 1979, 50, 1093-1099.

Shatz, M. On mechanisms of language acquisition: Can features of the communicative environment account for development? in L. Gleitmas \& E. Wanner (Eds.), Language acquisition: The stare of the art. New York: Cambridge University Press, in press.

Sinclair, H. Language and cognition in subnormals: $A$ Piagetian view. In N. O'Connor (Ed.), Language, cognitive deficits, and retardation. London: Butterworths, 1975. (a)

Sinclair, H. The role of cognitive structures in language acquisition. In E. H. Lenneberg \& E. Lenneberg (Eds.), Foundations of language development: A multidisciplinary approach. (Vol, 1). New York: Academic Press, 1975. Pp. 223-238. (b)

Slobin, D. Coznitive prerequisites for the development of grammar. In C. Ferguson \& D. Slobin (Eds.), Srudies of child language developmemt. New York: Holt, Rinehart \& Winston, 1973.

Slobin, D. The origins of grammatical encoding of events. Paper presented to Symposium "Beyond description in child language," Max-Planck-Gesellschaft Projektgruppe fur Psycholinguistik, Nijmegen. The Netherlands, 1979. In W. Devtsch, et al. (Eds.). The child's construction of language, in press.

Snow, C. E. Mother's speech to children lesarning language. Child Language, 1972, 43. 549.565.

Woods, B., \& Teuber, H. Changing parterns of childhood aphasia. Annals of Neturology. $1978,3(3), 273-280$.

Yamada, J. Preliminary evidenee for the independence of language from cognition: $A$ case study of a mentally retarded adolescent. UCLA Working Papers in Cognitive Linguistics, 1981. (a)

Yamada, J. Evidence for the independence of fangwage from cognition: A case study of a mentally retarded edolescent. Doctoral dissertation, University of California, Los Angles, 1981. (b)

Yamada, J. \& Curtiss, S. Language and cognition in a case of Turner's syndrome. UCL.A Working Popers in Cognitive Lingmistics, in press, 3.

Zukow, P., Reilly, 1.. \& Greenfield, P. Making the absent present: Facilitating the transition from sensori-motor to linguistic communication. In K. Nelson (Ed.), Children's tanguage. New York: Gardner Press, 1970. 